\title{
CDISC SDTM Findings About Object Terminology
}

National Cancer Institute

\section{Source}

National Cancer Institute. CDISC SDTM Findings About Object Terminology. NCI

Thesaurus. Code C101835.

Terminology associated with the findings about the object of the observation codelist of the Clinical Data Interchange Standards Consortium (CDISC) Standard Data Tabulation Model (SDTM). 